\title{
Pedro José Carrasco Parrilla
}

Universidad de Castilla-La Mancha

pedrojose.carrasco@uclm.es

ORCID 0000-0002-1669-513X

https://doi.org/10.26881/gsp.2020.1.08

\section{Los tributos locales en España}

\section{Introducción}

El presente trabajo surge con la finalidad de dar a conocer los tributos locales que existen en España, en unos momentos en los que la situación financiera y competencial de las Entidades Locales debería ser revisada en profundidad, máxime cuando a finales de julio del año 2017 se presentó por parte de la Comisión de expertos para la revisión del sistema de financiación local', el informe en el que se lleva a cabo un análisis de propuestas de reforma del sistema de financiación local, que también coincidió con la presentación por las mismas fechas del informe de la Comisión de expertos para la reforma del sistema de financiación autonómica².

Las Entidades Locales han sido relegadas al último lugar durante el proceso descentralizador llevado a cabo en España desde la vigente Constitución de 1978. Una de las principales características del actual sistema de financiación local es - además de la insuficiencia de recursos, provocada entre otros factores por el gran número de servicios que prestan las Administraciones locales, algunos llevados a cabo sin tener las correspondientes competencias, y más aún, como consecuencia de la crisis económica, que hizo reducir la actividad económica con la consiguiente reducción de ingresos, o la ralentización de la vida institucional como consecuencia de gobiernos carentes de mayorías parlamentarias que les dotaran de la necesaria estabilidad para llevar a cabo reformas necesarias y urgentes, como veremos, en el caso del Impuesto sobre Incremento del Valor de los Terrenos de Naturaleza Urbana - la importancia que tienen los tributos propios así como la gran dependencia de las transferencias corrientes del Estado y un desarrollo escaso de las participaciones en los ingresos de las Comunidades Autónomas, en su mayoría de carácter condicionado y vinculadas a finalidades específicas. Pero hasta que la esperada reforma vea la luz y con ella pueda garantizarse y dar mejor cumplimiento al principio de suficiencia financiera, así como una mejor

\footnotetext{
1 Cfr.: https://www.hacienda.gob.es/CDI/sist\%20financiacion\%20y\%20deuda/informacioneells/2017/informe_final_comisi\%C3\%B3n_reforma_sfl.pdf [consultado el 15.10.2019].

2 Cfr.: https://www.hacienda.gob.es/CDI/sist\%20financiacion\%20y\%20deuda/informaci\%C3\%B3nccaa/informe_final_comisi\%C3\%B3n_reforma_sfa.pdf [consultado el 15.10.2019].
} 
distribución de los recursos de acuerdo con los principios de autonomía, eficiencia, equidad y corresponsabilidad fiscal, en el presente trabajo trataremos de exponer los diferentes tributos que existen en ámbito local en España.

El artículo 142 de la Constitución Española reconoce a las haciendas locales (Ayuntamientos y Diputaciones Provinciales u otras Corporaciones de carácter representativo), como manifestación de su autonomía financiera, la potestad para establecer tributos, si bien su establecimiento y exigencia, según el artículo 133.2 de la propia Constitución, deberá realizarse "de acuerdo con la Constitución y las leyes".

Al carecer de potestad legislativa, los entes locales pueden establecer y exigir tributos de acuerdo con la habilitación conferida en la Ley 39/1988, de 28 de diciembre, Reguladora de las Haciendas Locales. Esta Ley fue sustituida por el Real Decreto Legislativo 2/2004, de 5 de marzo, por el que se aprueba el Texto Refundido de la Ley Reguladora de las Haciendas Locales (en adelante, TRLRHL; tal y como se dispone en su artículo 1, esta Ley se aplicará a todo el territorio nacional español, sin perjuicio de los regímenes financieros forales de los Territorios Históricos del País Vasco y Navarra, y de los tratados y convenios internacionales suscritos por España), en el que se establece el sistema de ingresos de los Ayuntamientos y Diputaciones Provinciales, integrado, junto a otros medios de financiación, por tributos propios (clasificados en tasas, contribuciones especiales e impuestos), así como recargos sobre tributos autonómicos o de otros entes locales.

Por lo que se refiere a la gestión, liquidación, inspección y recaudación de los tributos locales, se llevará a cabo de acuerdo con lo prevenido en la Ley 58/2002, de 17 de diciembre, General Tributaria y en las demás leyes del Estado reguladoras de la materia, así como en las disposiciones dictadas para su desarrollo. Ahora bien, mediante el ejercicio de la potestad reglamentaria - reconocida en el art. 12.2 del TRLRLH - materializado con la aprobación de Ordenanzas fiscales, los entes locales podrán adaptar esta normativa estatal al régimen de organización y funcionamiento interno propio sin que tal adaptación pueda ir en contra del contenido material de la normativa estatal.

Los tributos se definen en el artículo 2 de la Ley General Tributaria como "los ingresos públicos que consisten en prestaciones pecuniarias exigidas por una Administración pública como consecuencia de la realización del supuesto de hecho al que la ley vincula el deber de contribuir, con el fin primordial de obtener los ingresos necesarios para el sostenimiento de los gastos públicos".

Los tributos se clasifican en tasas, contribuciones especiales e impuestos. Aunque en este trabajo nos vamos a referir de un modo más detallado a los impuestos locales, veamos en primer lugar, en los dos siguientes apartados, los otros dos tipos de tributos que pueden exigirse en el ámbito de la hacienda local: las tasas y las contribuciones especiales; para continuar con los distintos impuestos exigibles en la hacienda local. 


\section{Las tasas}

Son definidas en la letra a) del artículo 2.2 de la Ley General Tributaria, como “los tributos cuyo hecho imponible consiste en la utilización privativa o el aprovechamiento especial del dominio público, la prestación de servicios o la realización de actividades en régimen de derecho público que se refieran, afecten o beneficien de modo particular al obligado tributario, cuando los servicios o actividades no sean de solicitud o recepción voluntaria para los obligados tributarios o no se presten o realicen por el sector privado".

El artículo 20.1 del TRLRLH dispone que las entidades locales, "en los términos previstos en esta ley, podrán establecer tasas por la utilización privativa o el aprovechamiento especial del dominio público local, así como por la prestación de servicios públicos o la realización de actividades administrativas de competencia local que se refieran, afecten o beneficien de modo particular a los sujetos pasivos", detallando a continuación, en consonancia con lo dispuesto en la Ley General Tributaria, que tendrán la consideración de tasas las prestaciones patrimoniales que establezcan las entidades locales por:

1. La utilización privativa o el aprovechamiento especial del dominio público local. En el apartado 3 de este artículo 20, a título ejemplificativo se detallan supuestos en los que cabe exigir una tasa por este concepto, entre otros por: la ocupación del subsuelo de terrenos de uso público local; la ocupación de terrenos de uso público local con mercancías, materiales de construcción, escombros, vallas, puntales, asnillas, andamios y otras instalaciones análogas; las entradas de vehículos a través de las aceras y reservas de vía pública para aparcamiento exclusivo, parada de vehículos, carga y descarga de mercancías de cualquier clase; ocupación de terrenos de uso público local con mesas, sillas, tribunas, tablados y otros elementos análogos, con finalidad lucrativa; instalación de quioscos en la vía pública; o el estacionamiento de vehículos de tracción mecánica en las vías de los municipios dentro de las zonas que a tal efecto se determinen y con las limitaciones que pudieran establecerse.

2. La prestación de un servicio público o la realización de una actividad administrativa en régimen de derecho público de competencia local que se refiera, afecte o beneficie de manera particular al sujeto pasivo, cuando se produzca cualquiera de las siguientes circunstancias:

"a. Que no sean de solicitud o recepción voluntaria para los administrados. A estos efectos no se considerará voluntaria la solicitud o la recepción por parte de los administrados:

- Cuando venga impuesta por disposiciones legales o reglamentarias.

- Cuando los bienes, servicios o actividades requeridos sean imprescindibles para la vida privada o social del solicitante.

b. Que no se presten o realicen por el sector privado, esté o no establecida su reserva a favor del sector público conforme a la normativa vigente". En el apartado 4 del citado precepto legal se detallan, entre otras actividades: la expedición de documentos 
solicitados por los particulares; la concesión de licencias o autorizaciones administrativas de autotaxis y demás vehículos de alquiler; otorgamiento de licencias urbanísticas, de apertura de establecimientos; o la recogida de residuos sólidos urbanos ${ }^{3}$.

No obstante, no se considerará tasa y por tanto tributo, las contraprestaciones económicas establecidas coactivamente percibidas por la prestación de servicios públicos a los que se refiere esta apartado 4 del artículo 20 del TRLRLH, siempre que se realicen de forma directa mediante personificación privada o mediante gestión indirecta; pues ese caso tendrán la condición de prestaciones patrimoniales de carácter público no tributario conforme a lo previsto en el artículo 31.3 de la Constitución española; y se detalla en el apartado 6 del citado artículo 20 que tendrán la consideración prestaciones patrimoniales de carácter público no tributario aquellas exigidas por la explotación de obras o la prestación de servicios, en régimen de concesión, sociedades de economía mixta, entidades públicas empresariales, sociedades de capital íntegramente público y demás fórmulas de Derecho privado. A pesar de no tener carácter tributario, y así lo ha reconocido la Sentencia del Tribunal Constitucional español, STC 63/2019, de 9 de mayo, "lo esencial es que su establecimiento se lleve a cabo bien por la propia ley, bien con arreglo a la misma", por lo que estas contraprestaciones económicas deberán regular mediante ordenanza municipal. Como ha afirmado el Fundamento Jurídico 5 de esta sentencia: "Lo que determina y justifica la reserva de ley es la coactividad, o lo que es lo mismo, la falta de libertad real y efectiva, de modo que la reserva del art. 31.3 CE tiene como uno de sus fundamentos el de "garantizar que las prestaciones que los particulares satisfacen a los entes públicos sean previamente consentidas por sus representantes", configurándose de este modo como "una garantía de autoimposición de la comunidad sobre sí misma y, en última instancia, como una garantía de la libertad patrimonial y personal del ciudadano" (STC 73/2017, de 8 de junio, FJ 2; con cita de las SSTC 185/1995, de 14 de diciembre, FJ 3; 233/1999, de 16 de diciembre, FFJ 7, 9 y 10; 3/2003, de 16 de enero, FJ 4, y 136/2011, de 13 de septiembre, FJ 11)". Y en el Fundamento Jurídico 7 añade: "el carácter tributario o de tarifa de la eventual participación en el coste del servicio por parte de sus usuarios dependerá y forma parte de la previa decisión del legislador acerca de cómo deba prestarse y financiarse el servicio. Ello constituye una opción que, formulada aquí en términos genéricos, no puede calificarse de irrazonable ni arbitraria o carente de toda justificación, sino que, por el contrario, entra dentro del margen de configuración del que goza el legislador en este ámbito y que, por lo expuesto, no resulta contradictoria con la doctrina de este Tribunal".

\section{Las contribuciones especiales}

Son tributos cuyo hecho imponible consiste en la obtención por el obligado tributario de un beneficio o de un aumento de valor de sus bienes como consecuencia de la

\footnotetext{
3 Un estudio detallado de las tasas puede consultarse en M.J. Fernández Pavés, Las tasas y los precios públicos, en AA.VV., Derecho Tributario Local, Barcelona 2008, págs. 47-80.
} 
realización de obras públicas o del establecimiento o ampliación de servicios públicos (letra b), artículo 2.2 LGT). En el ámbito local, el art. 28 del TRLRLH se refiere a la realización de obras públicas o el establecimiento o ampliación de servicios públicos, ambos de carácter local, llevados a cabo por las respectivas entidades locales que serán los sujetos activos del tributo.

Estamos ante un tributo en el que existe, a diferencia de los impuestos, cierta contraprestación pues el obligado a su pago lo es por ser titular de bienes o derechos cuyo valor aumenta como consecuencia del establecimiento o ampliación de un servicio público o por la realización de una obra pública y se ve especialmente beneficiado por ello, sin perjuicio de que ese beneficio también lo sea para toda la colectividad.

Otra de las características de este tributo es que su recaudación se encuentra afecta a sufragar la obra o el servicio por el que se hayan exigido, constituyendo su base imponible como máximo el $90 \%$ del coste que la entidad local soporte por la realización de obras o el establecimiento o ampliación del servicio público. Y no puede superar ese porcentaje pues, en efecto, los beneficiados por las obras o servicios pueden ser todos los habitantes del municipio que pretenda exigir este tributo pero de manera particular lo serán los especialmente beneficiados que son los que deberán sufragar el coste hasta el porcentaje legalmente establecido. No obstante la ley también limita el importe de la recaudación local al importe efectivamente satisfecho por el Ayuntamiento exactor, pues en numerosas ocasiones estas obras o servicios municipales pueden contar con subvenciones o ayudas económicas de otras instituciones provinciales, autonómicas, estatales, europeas...

Por último, y una vez determinada la base imponible de este tributo, procederá a repartirse la misma entre todos los sujetos pasivos (los especialmente beneficiados por la realización de la obra o la prestación del servicio público $\left.{ }^{4}\right)$ con arreglo a las normas establecidas en el art. 32.2 del TRLRLH (metros lineales de fachada de los inmuebles beneficiados, superficie, volumen edificable, entre otras).

\section{Los impuestos}

En relación con los impuestos locales, éstos se clasifican en impuestos de exigencia obligatoria por los ayuntamientos (Impuesto sobre Bienes Inmuebles, Impuesto sobre Actividades Económicas, e Impuesto sobre Vehículos de Tracción Mecánica), e impuestos facultativos o potestativos (Impuesto sobre Construcciones, Instalaciones y Obras, Impuesto sobre el Incremento del Valor de los Terrenos de Naturaleza Urbana, e Impuesto sobre Gastos Suntuarios en su modalidad de cotos privados de caza y pesca),

4 Como afirma Fernández Marín, "no bastará con la mera realización de la actividad administrativa, es decir, con la realización de una obra pública o el establecimiento o ampliación del servicio público, es necesario que éstas provoquen un beneficio especial"; cfr.: F. Fernández Marín: Estudio jurisprudencial de las contribuciones especiales, Almería 1999, pág. 17. También puede consultarse, del mismo autor: Las contribuciones especiales, en AA.VV., Derecho Tributario Local, Barcelona 2008, págs. 81-116. 
pues para su imposición y, en su caso, una vez establecidos, determinar su supresión, junto al resto de tasas y contribuciones especiales, deberán aprobar las correspondientes ordenanzas fiscales reguladoras de los mismos.

\subsection{Impuestos obligatorios}

\section{A. Impuesto sobre Bienes Inmuebles}

Estamos ante un tributo directo de carácter real que grava la riqueza inmobiliaria y gira en torno al concepto de valor catastral, que puede ser definido como el valor dado a cada inmueble por la Administración conforme a los criterios que se especifican en el Real Decreto Legislativo 1/2004, por el que se aprueba del Texto Refundido del Catastro Inmobiliario ${ }^{5}$. Se establecen tres tipologías de bienes inmuebles: rústicos, urbanos y de características especiales (definidos en el Real Decreto Legislativo 1/2004, del Catastro Inmobiliario).

Constituye su hecho imponible la titularidad de los siguientes derechos sobre los bienes inmuebles rústicos y urbanos y sobre los inmuebles de características especiales: De una concesión administrativa sobre los propios inmuebles o sobre los servicios públicos a que se hallen afectos; de un derecho real de superficie; de un derecho real de usufructo o del derecho de propiedad.

En el caso de inmuebles de uso residencial que se encuentren desocupados con carácter permanente, los ayuntamientos podrán exigir un recargo de hasta el 50 por ciento de la cuota líquida del impuesto. Este recargo, que se exigirá a los sujetos pasivos de este tributo, se devengará el 31 de diciembre y se liquidará anualmente por los ayuntamientos, una vez constatado y declarado mediante acto administrativo que el inmueble se encuentra desocupado. A los efectos de considerar que un inmueble está desocupado con carácter permanente el art. 72.4 del Texto Refundido se remite a lo que se establezca en la correspondiente normativa sectorial de vivienda, autonómica o estatal, con rango de ley, y conforme a los requisitos, medios de prueba y procedimiento que establezca la ordenanza fiscal del ayuntamiento que pretenda exigir el citado recargo. En todo caso, la declaración municipal como inmueble desocupado con carácter permanente exigirá la previa audiencia del sujeto pasivo, así como que el Ayuntamiento deberá acreditar indicios de que el inmueble está desocupado, y que deberán recogerse en la ordenanza reguladora del mismo, entre los que podrán figurar los relativos a los consumos de servicios de suministro.

Es un impuesto de devengo anual y de gestión compartida con la Administración del Estado.

\footnotetext{
5 Vid., en este sentido J. Rodríguez Márquez, Impuesto sobre Bienes Inmuebles, en AA.VV., Derecho Tributario Local, Barcelona 2008, pág. 118. Un estudio más detallado de este impuesto también puede consultarse en I. Merino Jara, E. Manzano Silva, Impuesto sobre bienes inmuebles, en P. Chico De La Cámara, J. Galán Ruiz (Dirs.), Los tributos locales y el régimen fiscal de los ayuntamientos, Pamplona 2014; así como E. Manzano Silva, Regulación actual y perspectivas de reforma del Impuesto sobre Bienes Inmuebles, en Revista Tributos Locales, Monografía n4, Hacia una futura reforma de los tributos locales, Madrid 2018, págs. 23-46.
} 


\section{B. Impuesto sobre Actividades Económicas}

Tributo directo de carácter real, cuyo hecho imponible está constituido por el mero ejercicio en territorio español de actividades empresariales, profesionales o artísticas, se ejerzan o no en local determinado y se hallen o no especificadas en las tarifas del impuesto. No se tiene en cuenta la habitualidad del ejercicio de la actividad económica como tampoco que exista ánimo de lucro o beneficio.

Se considera que una actividad se ejerce con carácter empresarial, profesional o artístico cuando suponga la ordenación por cuenta propia de medios de producción y de recursos humanos, o de uno de ambos, con la finalidad de intervenir en la producción o distribución de bienes o servicios.

Son sujetos pasivos las personas físicas y jurídicas y las entidades a que se refiere el artículo 35.4 de la Ley General Tributaria (herencias yacentes, comunidades de bienes y demás entidades que, carentes de personalidad jurídica, constituyan una unidad separada o un patrimonio susceptible de imposición), siempre que realicen en territorio español cualesquiera de las actividades que originan el hecho imponible. No obstante, en la actualidad, tras establecerse una exención general para las personas físicas así como para las personas jurídicas y entidades cuando no alcancen un importe neto de la cifra de negocios de un millón de euros, los únicos sujetos pasivos que están obligados al pago de este impuesto son las personas jurídicas y entidades que superen dicha cifra de negocios.

Las diputaciones provinciales, los consejos insulares de Baleares, los cabildos insulares de Canarias y las comunidades autónomas uniprovinciales (p.ej. Madrid, Murcia, Cantabria...) podrán establecer un recargo sobre el IAE, que se aplicará al importe de las cuotas municipales mínimas, modificadas por la aplicación del coeficiente de ponderación y cuyo tipo impositivo no podrá ser superior al 40\%. Para exigir este recargo es necesario que se adopte el correspondiente acuerdo de imposición, así como la aprobación de la ordenanza fiscal reguladora del mismo.

Estamos ante un impuesto de devengo anual y de gestión compartida con la Administración Tributaria del Estado ${ }^{6}$.

\section{Impuesto sobre Vehículos de Tracción Mecánica}

Impuesto real, directo y objetivo, cuyo hecho imponible constituye la titularidad de los vehículos de tracción mecánica aptos para circular por las vías públicas, cualquiera que sea su clase y categoría. Como elementos determinantes de la sujeción a este impuesto se encuentran el ser titular de ese tipo de vehículos, considerándose titular a la persona a cuyo nombre figure en el permiso de circulación del vehículo, así como que estemos ante vehículos de tracción mecánica aptos para circular por las vías públicas, considerándose que un vehículo es apto para circular por vías públicas si ha sido matriculado en los registros públicos correspondientes, mientras no haya causa-

6 Un estudio más detallado de este impuesto se lleva a cabo por J.A. Gómez Requena, Impuesto sobre Actividades Económicas, en P.J. Carrasco Parrilla (Dir.), Derecho tributario local y procedimientos tributarios, Barcelona 2019. 
do baja en éstos. También se consideran aptos, aunque no consten en ningún registro, los vehículos provistos de permisos temporales de circulación o de matrícula turística.

Sin perjuicio de que la normativa del impuesto establece supuestos de no sujeción y de exención al impuesto, será sujeto pasivo de este impuesto la personas a cuyo nombre conste el vehículo en el permiso de circulación, estableciéndose por tanto a los efectos de este impuesto, una identidad absoluta entre el titular del vehículo y el del permiso de circulación de mismo.

También es un impuesto de carácter periódico y se devenga el primer día del periodo impositivo, esto es, el 1 de enero de cada año, con carácter general, o bien el día de su adquisición, en el caso de que la misma tenga lugar a lo largo del periodo impositivo.

La gestión del impuesto corresponde al ayuntamiento del domicilio que conste en el permiso de circulación del vehículo7.

\subsection{Impuestos facultativos}

\section{A. Impuesto sobre Construcciones, Instalaciones y Obras}

El hecho imponible lo constituye la realización, dentro del término municipal, de cualquier construcción, instalación u obra para la que se exija la obtención de la correspondiente licencia urbanística, se haya obtenido o no dicha licencia, siempre que su expedición corresponda al Ayuntamiento de la imposición. La clave para determinar la sujeción a este impuesto está en la necesidad solicitar licencia para la realización de la construcción, instalación u obra que se va a ejecutar, con independencia de su otorgamiento.

Se considera sujeto pasivo, a título de contribuyente, al dueño de la obra, con independencia de si es el dueño del inmueble o no. Así, se considera dueño de la construcción, instalación u obra a quien soporte los gastos o el coste que comporte su realización. El concepto dueño de la obra hace referencia a la persona que la promueve y realiza, por sí o por tercero, asumiendo la obligación de sufragarla a su costa.

Con el fin de garantizar el pago del tributo, se establece la figura del sustituto del contribuyente, prevista para aquellos supuestos en los que la construcción, instalación u obra no se lleva a cabo por el sujeto pasivo contribuyente, que será quien solicite las correspondientes licencias o realice las construcciones, instalaciones $\mathrm{u}$ obras, de ahí que esté obligado a cumplir cuantas obligaciones se deriven de la realización del hecho imponible, incluso el pago del impuesto, con independencia de que posteriormente pueda repercutir la cuota tributaria al contribuyente.

La base imponible del impuesto está constituida por el coste real y efectivo de la construcción, instalación u obra (y se identifica con el coste de ejecución material, según jurisprudencia del Tribunal Supremo), del que no forma parte, el IVA y demás impuestos análogos propios de regímenes especiales, ni tampoco las tasas, precios

7 Puede consultarse un análisis más exhaustivo de este impuesto en P. Chico De La Cámara, Impuesto sobre Vehículos de Tracción Mecánica, en P. Chico De La Cámara, J. Galán Ruiz (Dirs.), Los tributos locales y el régimen fiscal de los ayuntamientos, Pamplona 2014, págs. 183-232. 
públicos y demás prestaciones patrimoniales de carácter público local relacionados con la construcción, instalación u obra, ni tampoco los honorarios de profesionales, el beneficio empresarial del contratista ni cualquier otro concepto que no integre, estrictamente, el coste de ejecución material.

La cuota de este impuesto será el resultado de aplicar a la base imponible el tipo de gravamen, que será fijado por cada ayuntamiento, sin que pueda exceder del $4 \%$.

El impuesto se devenga en el momento de iniciarse la construcción, instalación u obra, aun cuando no se haya obtenido la correspondiente licencia de obras o urbanística ${ }^{8}$.

\section{B. Impuesto sobre Incremento del Valor de los Terrenos de Naturaleza Urbana ${ }^{9}$}

Impuesto de carácter real y objetivo, pues ni el sujeto pasivo se incluye en la definición del hecho imponible, ni, en principio son tenidas en cuenta las circunstancias personales y familiares del contribuyente a la hora de calcular el impuesto; aunque se habilita a los Ayuntamientos para que establezcan una bonificación de las cuotas devengadas en las transmisiones lucrativas mortis causa a favor de descendientes y adoptados, cónyuge y ascendientes y adoptantes, lo cual deja en manos de los Ayuntamientos la opción de otorgarle cierto carácter subjetivo para este supuesto concreto que la normativa autoriza.

De carácter proporcional e instantáneo (a pesar de que para su cálculo se tenga en cuenta el aumento de valor experimentado en un máximo de 20 años). Como una de las posibles causas justificativas de su exigencia se encuentra la participación que el Ayuntamiento ha de tener en una parte de las plusvalías generadas en los terrenos de naturaleza urbana de propiedad particular por la actuación urbanística y la realización de obras y servicios públicos de las administraciones públicas (en efecto, el párrafo segundo del art. 47.2 de la Constitución española dispone: "La comunidad participará en las plusvalías que genere la acción urbanística de los entes públicos").

Constituye el hecho imponible el incremento de valor que experimenten los terrenos de naturaleza urbana (a efectos del Impuesto sobre Bienes Inmuebles) que se ponga de manifiesto a consecuencia de la transmisión de la propiedad de los mismos por cualquier título o con ocasión de la constitución o transmisión de cualquier derecho real de goce, limitativo del dominio, sobre aquéllos (los actos que pueden conlle-

8 Puede consultarse el trabajo llevado a cabo por A. Fornieles Gil, Impuesto sobre Construcciones, Instalaciones y Obras, en P.J. Carrasco Parrilla (Dir.), Derecho tributario local y procedimientos tributarios, Barcelona 2019; así como J. Galán Ruiz, La futura reforma de las haciendas locales: El Impuesto sobre Construcciones, Instalaciones y Obras, en Revista Tributos Locales, Monografía n4, Hacia una futura reforma de los tributos locales, Madrid 2018, págs. 101-163.

9 Un estudio más detallado de este impuesto puede consultarse en P.J. Carrasco Parrilla, Impuesto sobre Incremento del Valor de los Terrenos de Naturaleza Urbana, en P.J. Carrasco Parrilla (Dir.), Derecho tributario local y procedimientos tributarios, Barcelona 2019. También puede consultarse J.E. Varona Alabern, Presente y futuro del IIVTNU tras su declaración de inconstitucionalidad, en Revista Tributos Locales, Monografía n4, Hacia una futura reforma de los tributos locales, Madrid 2018, págs. 167-198; así como M.J. Fernández Pavés, ¿En qué situación está el impuesto de "plusvalía"? La posibilidad de inaplicación y obtención de devoluciones, Valencia 2018. 
var una transmisión de terrenos o derechos reales de goce pueden ser: compraventa, permuta, donación, herencia, expropiaciones forzosas, subastas judiciales y notariales, aportación de inmuebles a sociedades, entrega de inmuebles a cambio de pensión vitalicia).

Es sujeto pasivo, a título de contribuyente, el que obtiene para sí la ganancia que supone el incremento de valor, que es en las transmisiones de terrenos o en la constitución o transmisión de derechos reales de goce limitativos del dominio a título lucrativo, la persona que adquiera el terreno o a cuyo favor se constituya o transmita el derecho real de que se trate; mientras que en las operaciones anteriores, realizadas a título oneroso, será contribuyente la persona que transmita el terreno, o que constituya o transmita el derecho real de que se trate.

No obstante, si el contribuyente es una persona física no residente en España, la persona o entidad que adquiera el terreno o a cuyo favor se constituya o transmita el derecho real tendrá la consideración de sustituto del contribuyente.

En relación con la base imponible del impuesto, constituye la misma el incremento del valor de los terrenos puesto de manifiesto en el momento del devengo y experimentado a lo largo de un periodo máximo de veinte años, que puede o no coincidir con el valor real o el valor de mercado, puesto que se determina conforme a un procedimiento y unos porcentajes establecidos en el TRLRHL. No se trata de gravar el valor real o el valor de mercado, pues lo único que se considera a efectos de cuantificar el incremento es el "valor legal" del terreno en el momento de su transmisión, por lo que más bien parece que el impuesto pretende gravar es el incremento legal del valor del terreno de naturaleza urbana experimentado por la permanencia de más de un año en el patrimonio del transmitente, a diferencia del texto originario de 1988 que gravaba plusvalías reales. De ahí que se haya considerado que "este sistema ha aportado el efecto benéfico de la claridad y simplificación en el método o procedimiento de dicho cálculo de la base" (Sentencia del Tribunal Superior de Justicia de la Comunidad de Madrid, de 6-11-2003). Con ello se pueden ver afectados principios esenciales como el de capacidad económica, por ejemplo cuando el valor legal del terreno supere al valor de mercado del mismo. Precisamente algunos autores se mostraron muy críticos con la esta regulación del impuesto, basando sus argumentos en el supuesto en que no siempre pueden producirse plusvalías reales, considerando su exigencia en estos casos como una severa afrenta a la lógica tributaria y a los principios de justicia tributaria, ya que el método de cálculo empleado por la Ley se lleva a cabo en detrimento de la realidad económica, lo que supondría subordinar los principios de equidad, justicia y capacidad económica a la "comodidad administrativa" en la gestión del impuesto.

En este sentido, han sido cuatro las Sentencias del Tribunal Constitucional español las que han declarado inconstitucionales determinados preceptos de las normativas reguladoras de este impuesto, tres correspondientes al régimen foral (STC 26/2017, de 16 de febrero, en relación con la normativa foral del Territorio Histórico de Guipúzcoa; STC 37/2017, de 1 de marzo, en relación con la normativa foral del Territorio Histórico 
de Álava ${ }^{10}$; así como la STC 72/2017, de 5 de junio, en relación con la normativa foral de Navarra) y la STC 59/2017, de 11 de mayo, correspondiente al régimen común contenido en el TRLRHL, que a pesar de que en su FJ5 se afirma que el IIVTNU "no es, con carácter general, contrario al Texto Constitucional, en su configuración actual", declara la nulidad de los arts. 107.1, 107.2.a, y 110.4 del TRLRHL, en la medida en que sometieran a tributación situaciones de inexistencia de incremento de valor. No obstante, precisa el TC en este mismo FJ"que la forma de determinar la existencia o no de un incremento susceptible de ser sometido a tributación es algo que solo corresponde al legislador, en su libertad de configuración normativa, a partir de la publicación de esta Sentencia, llevando a cabo las modificaciones o adaptaciones pertinentes en el régimen legal del impuesto que permitan arbitrar el modo de no someter a tributación las situaciones de inexistencia de incremento de valor de los terrenos de naturaleza urbana".

A falta de modificación normativa de los preceptos afectados por la Sentencia del Tribunal Constitucional (a pesar de que el 9-3-2018 se presentó en el Congreso de Diputados la Proposición de Ley n¹22/000196 de reforma del IIVTNU para su adaptación a la jurisprudencia constitucional, y modificar TRLRHL, en la que se proponía un nuevo apartado 5 en el art. 104 LRHL según el cual no se producirá la sujeción al impuesto en las transmisiones de terrenos, respecto de las que el sujeto pasivo acredite la inexistencia de incremento de valor, por la diferencia entre los valores reales de transmisión y adquisición del terreno; debiendo declarar el sujeto pasivo la transmisión no sujeta así como aportar las pruebas que acrediten la inexistencia de incremento de valor), ha sido el Tribunal Supremo, en Sentencia 1163/2018, de 9 de julio de 2018, resolviendo en casación, quien ha procedido a establecer, en sus FD 5 y 7 :

- Que los artículos 107.1 y 107.2 a) del TRLRHL adolecen sólo de una inconstitucionalidad y nulidad parcial, siendo plenamente aplicables, en todos aquellos supuestos en los que el obligado tributario no ha logrado acreditar (pues a él corresponde probar la inexistencia de plusvalía), por "cualquier principio de prueba, que al menos indiciariamente permita apreciarla, como es la diferencia entre el valor de adquisición y el de transmisión que se refleja en las correspondientes escrituras públicas", o bien que haya optado "por una prueba pericial que confirme tales indicios" (consideramos que en ella deberían detallarse claramente los valores de adquisición y transmisión correspondientes al suelo urbano que demuestren la pérdida de valor del mismo); o bien que haya empleado "cualquier otro medio probatorio ex artículo 106.1 LGT que ponga de manifiesto el decremento de valor del terreno transmitido y la consiguiente improcedencia de girar liquidación por el IIVTNU. Precisamente (...), fue la diferencia entre el precio de adquisición y el de transmisión de los terrenos transmitidos la prueba tenida en cuenta por el Tribunal Constitucional en la STC 59/2017 para asumir -sin oponer reparo alguno- que, en

10 En relación con estas dos primeras Sentencias del Tribunal Constitucional español, puede consultarse "Plusvalía Municipal y Jurisprudencia Constitucional", Revista Tributos Locales, Monografía n³, Madrid 2017. 
los supuestos de hecho examinados por el órgano judicial que planteó la cuestión de inconstitucionalidad, existía una minusvalía".

- Que una vez que el obligado tributario aporte por cualquier medio la prueba de que el terreno no ha aumentado de valor, deberá ser la Administración la que pruebe en contra de dichas pretensiones para poder aplicar los preceptos del TRLRHL.

- "Contra el resultado de la valoración de la prueba efectuada por la Administración en el seno del procedimiento tributario correspondiente, el obligado tributario dispondrá de los medios de defensa que se le reconocen en vía administrativa y, posteriormente, en sede judicial. En la vía contencioso- administrativa la prueba de la inexistencia de plusvalía real será apreciada por los Tribunales de acuerdo con lo establecido en los artículos 60 y 61 LJCA y, en último término, y tal y como dispone el artículo 60.4 LJCA, de conformidad con las normas del Código Civil y de la Ley de Enjuiciamiento Civil".

- Que el artículo 104.1 del TRLHL (que es inconstitucional y nulo en todo caso pues, como establece la STC 59/2017, "no permite acreditar un resultado diferente al resultante de la aplicación de las reglas de valoración que contiene", esto es, porque impide "a los sujetos pasivos que puedan acreditar la existencia de una situación inexpresiva de capacidad económica") establece que el impuesto grava el incremento de valor que experimentan los terrenos, "y es la exégesis que el máximo intérprete de nuestra Constitución ha efectuado en la STC 59/2017 la que obliga a interpretar ese incremento de valor como un incremento de valor real para que la plusvalía gravada respete las exigencias que dimanan del principio de capacidad económica".

En suma, la STS viene a concretar a quién corresponde la carga de la prueba de la existencia de minusvalía, cuál debe ser el objeto de la prueba (la existencia de una minusvalía real), así como cuáles los medios de que dispone el sujeto pasivo para acreditar la existencia de un decremento de valor del terreno.

Por consiguiente, la base imponible del IIVTNU “ha de ser el resultado de multiplicar el valor del terreno en el momento del devengo por el número de años de generación del incremento y por el porcentaje anual que corresponda", tal y como ha establecido la Sentencia del Tribunal Supremo 1164/2019, de 11 de septiembre de 2019.

Pero lo que el Tribunal Supremo no entra a valorar (como tampoco lo hizo el TC), es lo ilógico de someter a tributación, por mínimo que fuera, todo incremento real del valor del terreno en función del período de generación de la plusvalía y no en función de su importe; esto es, sería el caso de un contribuyente con una cuota en el impuesto superior al incremento real del valor del terreno, a pesar de que en su FJ5 de la STS de 2018 citada, en relación con este supuesto manifestase que "esta Sala es consciente de que pudieran darse casos en los que la plusvalía realmente obtenida por el obligado tributario fuera tan escasa que la aplicación de los artículos 107.1 y 107.2 a) del TRLH pudiera suscitar dudas desde la perspectiva del artículo 31.1 CE. La cuestión, sin embargo, no se nos ha planteado aún y tampoco ha sido resuelta por el Tribunal Constitucional en la STC 59/2017". No obstante, el Auto del TS de 1 de julio de 2019, sí que plantea cuestión de inconstitucionalidad en relación con los apartados 1, 2a) y 4 del 
art. 107 del TRLRHL: "habida cuenta de su eventual oposición a los principios de capacidad económica y, específicamente, de prohibición de confiscatoriedad, que proclama el artículo 31.1 CE", siendo admitida a trámite por el TC en 16 de julio de 2019. Esta cuestión de inconstitucionalidad se suma a la del Juzgado de lo Contencioso-Administrativo n³2 de Madrid, de 8 de febrero de 2019, que ha sido resuelta por la STC 126/2019, de 31 de octubre de 2019, en la que se declara la inconstitucionalidad del impuesto cuando el importe a pagar por el contribuyente supere el incremento realmente obtenido, ya que se estaría vulnerando los principios de capacidad económica y no confiscatoriedad contenidos en el art. 31.1 CE, limitando las situaciones susceptibles de revisión a aquellas que no han adquirido firmeza a la fecha de su publicación ${ }^{11}$. A su vez, la Sentencia 126/2019, de 31 de octubre, hace un llamamiento al legislador pues, declarados inconstitucionales los arts. 107.1, 107.2 a) y 110.4 del TRLRHL por la STC 59/2017 y, en esta Sentencia, el art. 107.4 TRLRHL, "es tarea del legislador, en el ejercicio de su libertad de configuración normativa, realizar la adaptación del régimen legal del impuesto a las exigencias constitucionales puestas de manifiesto en una y otra sentencia", recordándonos que "de conformidad con el art. $31.1 \mathrm{CE}$, los ciudadanos no solo tienen el deber constitucional de contribuir al sostenimiento de los gastos públicos, sino también el derecho de hacerlo, no de cualquier manera, sino únicamente «con arreglo a la ley» y exclusivamente «de acuerdo con su capacidad económica»".

Pero lo más sorprendente de la regulación de este impuesto, abocado a su desaparición o a una reforma en profundidad, sobre todo si tenemos en cuenta las diferentes declaraciones de inconstitucionalidad y las dudas que suscitan algunas de las sentencias del TC, es que hayan transcurrido más de dos años desde la publicación de la STC

11 Establece el TC en esta Sentencia 126/2019, de 31 de octubre, en su FJ4, que "en aquellos supuestos en los que de la aplicación de la regla de cálculo prevista en el art. 107.4 TRLHL (porcentaje anual aplicable al valor catastral del terreno al momento del devengo) se derive un incremento de valor superior al efectivamente obtenido por el sujeto pasivo, la cuota tributaria resultante, en la parte que excede del beneficio realmente obtenido, se corresponde con el gravamen ilícito de una renta inexistente en contra del principio de capacidad económica y de la prohibición de confiscatoriedad que deben operar, en todo caso, respectivamente, como instrumento legitimador del gravamen y como límite del mismo (art. 31.1 CE)". Ahora bien, tal y como reitera esta Sentencia, el alcance de la declaración de inconstitucionalidad "debe serlo únicamente en aquellos casos en los que la cuota a satisfacer es superior al incremento patrimonial realmente obtenido por el contribuyente. Eso sí, la inconstitucionalidad así apreciada no puede extenderse, sin embargo (...) al art. 108.1 TRLHL (tipo de gravamen), pues el vicio declarado se halla exclusivamente en la forma de determinar la base imponible y no en la de calcular la cuota tributaria" (FJ5); añadiendo, por exigencia del principio de seguridad jurídica, una precisión sobre el alcance concreto del fallo, pues únicamente se considerarán situaciones susceptibles de ser revisadas con fundamento en esta Sentencia aquellas que, a la fecha de su publicación no hayan adquirido firmeza por haber sido impugnadas en tiempo y forma, y no haber recaído todavía en ellas una resolución administrativa o judicial firme. Incluso de esta Sentencia 126/2019 parece colegirse además, si tomamos en consideración los antecedentes del supuesto de hecho enjuiciado, que se estaría admitiendo por parte del TC que para la determinación del incremento patrimonial realmente obtenido por el contribuyente deberían tenerse en cuenta los gastos y tributos soportados tanto en la adquisición como en la transmisión, pues en la misma se establece que la declaración de inconstitucionalidad del art. 107.4 del TRLRHL "debe serlo únicamente en aquellos casos en los que la cuota a satisfacer es superior al incremento patrimonial realmente obtenido por el contribuyente". 
59/2017 sin haberse adecuado su regulación normativa a las exigencias constitucionales, máxime cuando el principio de seguridad jurídica exige además de la claridad y la certeza del ordenamiento jurídico aplicable, la confianza legítima y la previsibilidad de sus efectos, en el sentido de la expectativa de los contribuyentes fundada razonablemente en cuál ha de ser la actuación de los poderes públicos en la aplicación del Derecho, tal y como dispuso el FJ5 de la STC 135/2018, de 13 de diciembre, y reitera ahora también en su FJ5 la STC 126/2019, de 31 de octubre de 2019.

La cuota del impuesto será el resultado de aplicar a la base imponible los tipos correspondientes de la escala de gravamen, la cual será fijada por el Ayuntamiento, sin que el tipo impositivo pueda ser superior al $30 \%$.

\section{Impuesto sobre Gastos Suntuarios en su modalidad de cotos privados de caza y pesca ${ }^{12}$}

Dentro de los impuestos municipales de carácter facultativo se encuentra incluido el Impuesto Municipal sobre Gastos Suntuarios, si bien, es el único impuesto local que no encuentra su regulación sustantiva en el TRLRLH (por ello, y sin perjuicio de una reforma en cuanto a su estructura y elementos, en consonancia con las recomendaciones llevadas a cabo en el Informe de la Comisión de expertos para la revisión del modelo de financiación local de julio de 2017, sería deseable su inclusión en la citada norma, otorgándole de este modo una mayor seguridad jurídica).

Su carácter potestativo se contemplaba en el art. 231.1 del Texto Refundido de las disposiciones legales vigentes en materia de Régimen Local, aprobado por Real Decreto Legislativo 781/1986, y que con carácter residual, en su modalidad de aprovechamiento de cotos privados de caza y pesca, puede continuar exigiéndose por los Ayuntamientos.

El hecho imponible estará constituido por los aprovechamientos de los cotos privados de caza y pesca, independientemente de la forma de explotación o disfrute de los mismos.

Por lo que se refiere a los "cotos privados de caza y pesca", se establece que para delimitar estos conceptos se estará a lo que dispone la legislación administrativa específica en dicha materia. Así, para los cotos de caza tenemos que acudir a la Ley y Reglamento de Caza estatal que es donde se define el concepto de coto privado de caza. Según establece el art. 15 de la Ley de Caza, Ley 1/1970, de 4 de abril, debemos entender por coto de caza "toda superficie continua de terrenos susceptible de aprovechamiento cinegético que haya sido declarada y reconocida como tal, mediante resolución del Servicio de Pesca Continental, Caza y Parques Nacionales". La constitución de cotos privados de caza por los particulares propietarios o titulares de derechos reales o personales de los terrenos cinegéticos se regula en el artículo 16 de la Ley (Disposición que era desarrollada por el art. 18 del Reglamento de la Ley de Caza, aprobado por Decreto 506/1971, de 25 de marzo. Este reglamento ha estado vigente hasta el 28 de marzo de 2010, fecha de entrada en vigor del Real Decreto 367/2010, de 26 de marzo, de modificación de diversos re-

12 Puede consultarse un estudio más detallado de este impuesto en P.J. Carrasco Parrilla, Impuesto sobre aprovechamientos privados de cotos de caza y pesca, en P.J. Carrasco Parrilla (Dir.), Derecho tributario local y procedimientos tributarios, Barcelona 2019. 
glamentos del área de medio ambiente para su adaptación a la Ley 17/2009, de 23 de noviembre, sobre el libre acceso a las actividades de servicios y su ejercicio, y a la Ley $25 / 2009$, de 22 de diciembre, de modificación de diversas Leyes para su adaptación a la Ley de libre acceso a actividades de servicios y su ejercicio. No obstante, mantendrá su vigencia en aquellas comunidades y ciudades autónomas que no tengan normativa aprobada en la materia, en tanto no se dicte dicha normativa.).

Problema distinto es el que plantean los cotos de pesca, regulados en la Ley y Reglamento de Pesca Fluvial, de 20 de febrero de 1942 y 6 de abril de 1943, respectivamente, pues debemos matizar que no pueden existir cotos privados en este ámbito ya que forman parte del dominio público, siendo por tanto de titularidad administrativa los ríos y sus márgenes; de ahí que la referencia a los cotos privados de pesca debamos entenderla realizada a los cotos de pesca sobre los que los particulares ostenten derechos de aprovechamiento privativo o especial mediante concesión administrativa.

Además, debemos precisar que a las Comunidades Autónomas se les atribuye las competencias en materia de caza y pesca fluvial en virtud del art. 148.1.11 ${ }^{1}$ de la Constitución Española, por lo que las referencias a los organismos de carácter estatal deben entenderse hechas a los correspondientes de las respectivas Consejerías de las Comunidades Autónomas que hayan asumido las competencias en las citadas materias. Aún más, todas las Comunidades Autónomas han hecho uso de esta competencia, estableciendo leyes propias de caza y pesca. Así, por ejemplo, la Ley 1/1992, de Pesca Fluvial de la Comunidad Autónoma de Castilla-La Mancha, en su artículo 8.3 define los cotos de pesca como "aquellos cursos, tramos de cursos o masas de agua en los que la intensidad de la práctica de la pesca, realizada con finalidad exclusivamente deportiva, está regulada para aprovechar ordenadamente los recursos piscícolas".

Están obligados al pago del impuesto, según el art. 373.d) del TR de 1986, en concepto de contribuyentes, los titulares de los cotos o las personas a las que corresponda por cualquier título el aprovechamiento de caza o pesca en el momento de devengarse el Impuesto. Sin embargo, la figura del contribuyente queda eclipsada con el establecimiento de la del sustituto del contribuyente que va a recaer en el propietario de los bienes acotados, teniendo derecho a exigir del titular del aprovechamiento el importe del Impuesto para hacerlo efectivo en el municipio en cuyo término radique el coto de caza, pesca o la mayor parte de él. El establecimiento de la figura del sustituto no se lleva a cabo de manera gratuita pues la relación entre ambos sujetos pasivos es patente: para la constitución del coto es precisa la autorización del propietario del terreno a acotar al titular del derecho cinegético (autorización, que se exigía por escrito en el art. 18.2 del Reglamento de Caza, y se sigue exigiendo en la normativa de las distintas Comunidades Autónomas).

La base de este impuesto está representada por el valor del aprovechamiento cinegético o piscícola, que será fijado por los Ayuntamientos, con sujeción al procedimiento instituido para la aprobación de las ordenanzas fiscales, valor que será determinado mediante tipos o módulos que atiendan a la clasificación de fincas en distintos grupos, según sea su rendimiento medio por unidad de superficie. El art. 374.d) del Texto Refundido de 1986 establece que "estos grupos de clasificación y el valor asignable se fijarán 
mediante orden conjunta de los Ministerios de Economía y Hacienda, y Administración Territorial, oyendo previamente al de Agricultura, Pesca y Alimentación".

El tipo del impuesto no podrá exceder del $20 \%$, por lo que se deja libertad a los Ayuntamientos para variar éste a la baja, siendo la cuota tributaria el resultado de aplicar a la base imponible el tipo de gravamen correspondiente.

A pesar de que la regulación de este impuesto se encuentra fuera del TRLRLH, consideramos que puede ser de aplicación la bonificación de hasta el 5\% que contempla el art. 9.1 del citado texto legal, en el caso de que los ayuntamientos hayan decidido establecerla en la correspondiente ordenanza fiscal aplicable a las domiciliaciones de deudas de vencimiento periódico en entidades financieras, anticipos de pagos o realización de actuaciones que impliquen colaboración en la recaudación de ingresos.

El impuesto se devengará el 31 de diciembre de cada año, correspondiendo al Ayuntamiento de imposición la titularidad de las competencias de gestión.

\section{Conclusiones}

En este trabajo se ha intentado exponer los diferentes tributos que existen en el ámbito local en España, en unos momentos en los que la situación financiera y competencial de las Entidades Locales debería ser revisada en profundidad, no sólo porque desde finales de julio de 2017 se presentase, entre otros, el informe de la Comisión de expertos para la revisión del sistema de financiación local, en el que se llevan a cabo propuestas de reforma del sistema de financiación local, sino también por la pérdida de ingresos fiscales producida en este ámbito como consecuencia de la crisis económica, sino también por la ralentización de la vida institucional como consecuencia de gobiernos carentes de mayorías parlamentarias que les dotaran de la necesaria estabilidad para llevar a cabo reformas necesarias y urgentes, como ha quedado expuesto, en el caso del Impuesto sobre Incremento del Valor de los Terrenos de Naturaleza Urbana.

A pesar de que los entes locales carecen de potestad legislativa, éstos pueden establecer y exigir tributos de acuerdo con la habilitación conferida en el Real Decreto Legislativo 2/2004, en virtud de la cual, mediante el ejercicio de la potestad reglamentaria, aprueban las correspondientes Ordenanzas fiscales, con las que los entes locales podrán adaptar la normativa estatal al régimen de organización y funcionamiento interno propio.

Los tributos que pueden exigir los entes locales se clasifican en tasas, contribuciones especiales e impuestos, pudiendo ser estos últimos de exigencia obligatoria (Impuesto sobre Bienes Inmuebles, Impuesto sobre Actividades Económicas e Impuesto sobre Vehículos de Tracción Mecánica) e impuestos facultativos (Impuesto sobre Construcciones, Instalaciones y Obras, Impuesto sobre Incremento del Valor de los Terrenos de Naturaleza Urbana, e Impuesto sobre Gastos Suntuarios en su modalidad de cotos privados de caza y pesca). 


\section{Bibliografía}

Carrasco Parrilla P.J., Impuesto sobre aprovechamientos privados de cotos de caza y pesca, en P.J. Carrasco Parrilla (Dir.), Derecho tributario local y procedimientos tributarios, Barcelona 2019.

Carrasco Parrilla P.J., Impuesto sobre Incremento del Valor de los Terrenos de Naturaleza Urbana, en P.J. Carrasco Parrilla (Dir.), Derecho tributario local y procedimientos tributarios, Barcelona 2019.

Chico De La Cámara P., Impuesto sobre Vehículos de Tracción Mecánica, en P. Chico De La Cámara, J. Galán Ruiz (Dirs.), Los tributos locales y el régimen fiscal de los ayuntamientos, Pamplona 2014.

Fernández Marín F., Estudio jurisprudencial de las contribuciones especiales, Almería 1999.

Fernández Marín F., Las contribuciones especiales, en AA.VV., Derecho Tributario Local, Barcelona 2008.

Fernández Pavés M.J., Las tasas y los precios públicos, en AA.VV., Derecho Tributario Local, Barcelona 2008.

Fernández Pavés M.J., ¿En qué situación está el impuesto de "plusvalía"? La posibilidad de inaplicación y obtención de devoluciones, Valencia 2018.

Fornieles Gil A., Impuesto sobre Construcciones, Instalaciones y Obras, en P.J. Carrasco Parrilla (Dir.), Derecho tributario local y procedimientos tributarios, Barcelona 2019.

Galán Ruiz J., La futura reforma de las haciendas locales: El Impuesto sobre Construcciones, Instalaciones y Obras, en Revista Tributos Locales, Monografía n4, Hacia una futura reforma de los tributos locales, Madrid 2018.

Manzano Silva E., Regulación actual y perspectivas de reforma del Impuesto sobre Bienes Inmuebles, en Revista Tributos Locales, Monografía n4, Hacia una futura reforma de los tributos locales, Madrid 2018.

Merino Jara I., Manzano Silva E., Impuesto sobre bienes inmuebles, en P. Chico De La Cámara, J. Galán Ruiz (Dirs.), Los tributos locales y el régimen fiscal de los ayuntamientos, Pamplona 2014.

Requena J.A., Impuesto sobre Actividades Económicas, en P.J. Carrasco Parrilla (Dir.), Derecho tributario local y procedimientos tributarios, Barcelona 2019.

Rodríguez Márquez J., Impuesto sobre Bienes Inmuebles, en AA.VV., Derecho Tributario Local, Barcelona 2008.

Varona Alabern J.E., Presente y futuro del IIVTNU tras su declaración de inconstitucionalidad, en Revista Tributos Locales, Monografía n4, Hacia una futura reforma de los tributos locales, Madrid 2018.

\section{Streszczenie}

\section{Pedro José Carrasco Parrilla}

\section{Podatki lokalne w Hiszpanii}

Celem artykułu jest przedstawienie podatków lokalnych w Hiszpanii w czasie, gdy sytuacja finansowa i kompetencje jednostek samorządu terytorialnego powinny stać się przedmiotem dokładnej analizy. Pod koniec lipca 2017 r. komisja ekspertów powołana do dokonania prze- 
glądu lokalnego systemu finansowania przedstawiła raport, w którym zawarto analizę propozycji reformy systemu finansowania na poziomie lokalnym. W procesie decentralizacji, który miał miejsce po wejściu w życie obecnej Konstytucji w 1978 r., pozycja władz lokalnych została wyraźnie zdegradowana. Jeżeli proponowane reformy ujrzą światło dzienne, w pełni zostanie zagwarantowana i lepiej będzie przestrzegana zasada wystarczalności finansowej, jak również wdrożony zostanie lepszy podział zasobów zgodnie z zasadami autonomii, wydajności, sprawiedliwości i współodpowiedzialności fiskalnej. W oczekiwaniu na to autor przedstawia różnego rodzaju podatki obecnie występujące na poziomie lokalnym w Hiszpanii.

\section{Summary}

\section{Pedro José Carrasco Parrilla}

\section{Local taxes in Spain}

The purpose of the article is to present local taxes in Spain at a time when the financial situation and competences of local government units should be thoroughly analyzed. At the end of July 2017 a commission of experts established to review the local financing system presented a report which carries out an analysis of proposals to reform the local financing system. In the decentralization process that has taken place since the entrance into force of the current Constitution in 1978, local authorities have been relegated to last place. If the proposed reforms see the light, the principle of financial sufficiency will be fully guaranteed and better complied with and the better distribution of resources in accordance with the principles of autonomy, efficiency, equity and fiscal co-responsibility will be implemented. Pending this, the author presents different taxes that exist at local level in Spain.

Słowa kluczowe: podatki komunalne, finanse lokalne, zarządzanie podatkami komunalnymi, władza ustawodawcza, władza regulacyjna, podatki obowiązkowe, podatki fakultatywne

Keywords: council taxes, local finances, municipal tax management, legislative power, regulatory power, compulsory taxes, optional taxes 